\title{
¿Por qué estudiar Derecho Animal?
}

Keywords: animales como cosas; animales seres sensibles; bienestar animal en la UE; enseñanza del Derecho Animal

Nuestro ordenamiento adopta, respecto a los animales, el estatuto jurídico de cosas en propiedad, como visión, orientada por la configuración histórica, que compendia y transmite la Codificación napoleónica a todos los regímenes jurídicos codificados. Sin embargo, la uniformidad impuesta por esta concepción, se ha roto en fechas relativamente recientes en tres países europeos (además de en Cataluña), en coherencia con los dictados y orientaciones de numerosas normas, directivas y protocolos de la UE, que vienen subrayando la condición jurídica de los animales como "sentient beings” (seres sintientes).

La normativa europea ciñe las legislaciones y políticas de los Estados Miembros, a una consideración de los animales que choca frontalmente con el estatuto de "cosa" (objeto) que establecen nuestros derechos codificados. Por ello, y como muestra de una técnica jurídica coherente, Austria, Alemania y Suiza reformaron en fechas recientes sus respectivos Códigos civiles, sacando a los animales del tratado de propiedad, calificándolos como "no-cosas", antes de reformar, en el mismo sentido, sus respectivas Constituciones. En el caso de Alemania, para reconocer que es ésta, la de la protección animal y de la naturaleza: “...una obligación que el Estado asume frente a las generaciones futuras”.

Por estas razones, se trata de ahondar en la condición jurídica de los animales y revisar algunas cuestiones abiertas, que la sociedad demanda, como la regulación de las entidades protectoras, refugios y centros de acogida, en su papel de transmisores o creadores de un vínculo de adopción; la situación de los particulares que, a la hora de su muerte, se preocupan por el futuro de sus animales de compañía; la incidencia de las separaciones y divorcios en el régimen de asistencia de los animales de compañía; la necesidad de una regulación precisa de las Terapias Asistidas con Animales, que presentan un desarrollo creciente en nuestro país; la prevención y sanción de las conductas violentas con los animales, que son signo de conductas asociales, como demuestran estudios bien fundados. En suma, todas las cuestiones en las que el Estado, como tal, tiene facultades normativas, a las que una ley marco de bienestar animal podría dotar de coherencia, previsión y univocidad, frente a la gran dispersión y diferencias de tratamiento que, en este tema, impera en la actualidad. En este sentido, la cuestión es, qué puede y debe hacer la Universidad para lograr dar un paso adelante en la búsqueda de nuevas soluciones y para adecuar el sistema jurídico, respecto a los animales, a las exigencias que la sociedad de hoy demanda

La transversalidad es uno de los resultados más relevantes del nuevo EEES. En este sentido, las llamadas hasta ahora asignaturas (en adelante materias), precisan de un nuevo diseño que no quede en una simple aplicación dispersa de las TIC dentro de las estrategias e-learning. La metodología de enseñanza y aprendizaje, así como la evaluación deben reestructurarse y adaptarse a los cambios que se desprenden de la enseñanza basada en problemas y la evaluación por competencias.

La Universidad está creciendo y evolucionando a un ritmo tan rápido como el que implica encontrarnos inmersos en una sociedad globalizada, por ello conviene detectar temas interés emergentes que se imponen como rutas por donde se canalizará la demanda social de nuevos profesionales. Nuestra contribución es adelantarnos a esas necesidades emergentes y reestructurar disciplinas hasta ahora desconectadas y dispersas en diferentes licenciaturas, masters o programas de doctorado. El esfuerzo de algunos de nosotros, se plasma en propuestas concretas, que apuntan a redefinir y evaluar las competencias que la sociedad demanda a los universitarios, dentro de un campo concreto, que es el del Derecho Animal y, como consecuencia, en la regulación jurídica del Bienestar Animal. 
El Eurobarómetro, desde Noviembre de 2005, ha venido identificando el bienestar animal como una de las 5 prioridades para una gran mayoría de ciudadanos europeos. En Enero de 2006 y Noviembre de 2006, la UE Commissión with the Animal Welfare Action Plan (23.1.2006) y el Council of Europe and the World Organisation for Animal Health (24.11.2006), reconocieron dicha prioridad y acordaron el seguimiento de un plan dirigido a introducir en los sistemas legislativos europeos, medidas tendentes al tratamiento del animal como ser sensible ("sentient being"). La sociedad parece estar yendo en este tema por delante de las legislaciones. Por lo demás, la última Estrategia General de la Comisión de UE (“A new Animal Health Strategy for the European Union (2007-2013) where 'Prevention is better than cure'; Communication from the Commission to the Council, the European Parliament, the European Economic and Social Commitee and the Commitee of the Regions. COM 539 [2007] ), pretende conseguir el objetivo de aunar tres pilares hasta ahora independientes, a saber: Bienestar Animal, Salud Pública, Seguridad Alimentaria. Esta nueva demanda de la UE, que será imperativa en la sociedad en el curso de pocos años, no puede dejarse atrás1. La Universidad española merece tener estudios pioneros de este ámbito, como ocurrirá en breve en las Universidades europeas y, desde los años 80, viene sucediendo en las principales Universidades de USA.

Actualmente el Bienestar Animal se estudia en las Facultad de Veterinaria (Etología), Filosofía (Ética de la naturaleza), Ciencias Ambientales, Biología, y, desde el año 2007-2008, se estudia el Derecho Animal, por primera vez en España, en la Facultad de Derecho de la Universitat Autònoma de Barcelona.

Los Proyectos que viene desarrollando el Grupo de Investigación ADS-UAB, que dirijo desde hace unos años, apunta a unificar y redefinir estas “asignaturas”, en una materia de común interés y enseñanza, accesible a todos los universitarios que encaucen su futuro profesional en el ámbito en el que la relación Humanos-Animales se entrecruza. Es decir, abogados, desde luego, biólogos, veterinarios, especialistas en ciencias medioambientales, es decir, cuantos en el futuro puedan ser agentes relevantes y creadores de corrientes de opinión y participación social. No se trata de una propuesta particularista, sino que aspira a servir de marco para que pueda aplicarse en las restantes Universidades españolas.

En este sentido el Master en Derecho Animal y Sociedad, que ahora en Octubre inicia su tercera edición, trata de potenciar el conocimiento y la reflexión sobre los animales desde un punto de vista jurídico y en un contexto global. Cada vez más se requieren expertos en Derecho Animal, con una visión certera y amplia de qué demanda la sociedad. Profesionales que puedan insertarse en la industria, en la abogacía, en la administración, en los organismos internacionales. Con esa ilusión, con ese empeño, trabajamos cada día. 